\title{
Inter-rater agreement of the Turkish version of the Neurobehavioral Rating Scale-Revised form
}

Aytül Çakcı, ${ }^{1}$ Jale Meray, ${ }^{2}$ Sibel Örsel, ${ }^{3}$ Rıdvan Alaca, ${ }^{4}$ Canan Çulha, ${ }^{5}$ İbrahim Gündoğdu, ${ }^{1}$ Evren Yaşar, ${ }^{4}$ Derya Öztuna, ${ }^{6}$ Eda Gürcay, ${ }^{1}$ Ebru Umay,,${ }^{1}$ Erhan Öztürk, ${ }^{1}$ Süheyla Bulut, ${ }^{3}$ Uğur Tamkan, ${ }^{1}$ Neslihan Metli, ${ }^{5}$ Musa Polat, ${ }^{2}$ Fevzi Öztekin ${ }^{7}$

${ }^{1}$ Department of Physical Medicine and Rehabilitation, Ankara Dışkapı Ylldırım Beyazt Training and Research Hospital, Ankara, Turkey

${ }^{2}$ Department of Physical Medicine and Rehabilitation, Medical Faculty of Gazi University, Ankara, Turkey

${ }^{3}$ Department of Psychiatry, Ankara Dışkapı Yıldırım Beyazıt Training and Research Hospital, Ankara, Turkey

${ }^{4}$ Department of Physical Medicine and Rehabilitation, Gülhane Military Medical Academy, Ankara, Turkey

${ }^{5}$ Department of Physical Medicine and Rehabilitation, Ankara Physical Medicine and Rehabilitation Training and Research Hospital, Ankara, Turkey

${ }^{6}$ Department of Statistics, Medical Faculty of Ankara University, Ankara, Turkey

${ }^{7}$ Department of Neurology, Ankara Dışkapı Yıldırım Beyazıt Training and Research Hospital, Ankara, Turkey

Received: February 2016 Accepted: April 2016

\section{ABSTRACT}

Objectives: This study aims to adapt the Neurobehavioral Rating Scale-revised form (NBRS-R) for Turkish traumatic brain injury (TBI) patients and to investigate the inter-rater agreement of the Turkish revised scale.

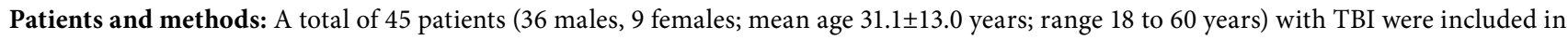
this study between September 2013 and August 2014. A semi-structured interview was set up for Turkish patients using a multidisciplinary approach (physiatrist, psychiatrist, neurologist and psychologist) with the participation of four rehabilitation centers. Questions were prepared for each of the 29 items, based on the recommendations of the original NBRS-R form. Four different interviewers from the four centers applied this form to a total of 45 TBI patients.

Results: The items evaluated by intra-class correlation coefficient showed satisfactory stability and the reliability of the items ranged from moderate to very good.

Conclusion: The NBRS-R form can be suggested to provide a reliable and easily reproducible evaluation method of neurobehavioral deficits in TBI patients who speak Turkish.

Keywords: Cognition; Neurobehavioral Rating Scale-Revised form; traumatic brain injury.

Traumatic Brain Injury (TBI) can cause important neurobehavioral disturbances. ${ }^{[1]}$ Patients with moderate and severe TBI in particular exhibit cognitive, emotional, behavioral and personality changes. ${ }^{[2,3]}$ Several studies have shown that these impairments can lead to impairments in daily live and social integration. It may also be difficult for people with TBI to return to work. The rehabilitation and recovery process is also negatively affected if these problems persist and cannot be accurately detected. ${ }^{[4-6]}$

Efficient and comprehensive assessment should include the precise measurement of cognitive, emotional and behavioral symptoms to be able to understand the various clinical, pathophysiological and therapeutic aspects of patients with TBI.

Quantitative measurability of neurobehavioral recovery makes it possible for these measures to be used as a secondary measurement method to rate outcome. Several neurobehavioral scales are widely used throughout the world. These include: The Neurobehavioral Functioning Inventory (NFI), the Neurobehavioral Rating Scale (NBRS), Behavior Rating Inventory of Executive Functions (BRIEF), the Dysexecutive Questionnaire (DEX), the Frontal Behavior Inventory (FBI), the Frontal Systems Behavior Scale (FrSBe), the Iowa Rating Scales of Personality

Corresponding author: Ebru Umay, MD. Ankara Dışkapı Ylldırım Beyazıt Ĕgitim ve Araştırma Hastanesi Fiziksel Tıp ve Rehabilitasyon Kliniği, 06110 Altındağ, Ankara, Turkey. e-mail: ebruumay@gmail.com 
Change (IRSPC) and the Neuropsychiatric Inventory (NPI). ${ }^{[7]}$

The Neurobehavioral Rating Scale-revised (NBRS-R) is a widely-used measurement around the world, which focus specifically on TBI patients. ${ }^{[1,7-9]}$ It appears to be a more sensitive tool for monitoring neurobehavioral disturbances, and can be easily applied by physiatrists in rehabilitation clinics.

In this study, since neurobehavioral symptoms may not be easily identifie, and as away of overcoming the challenges faced by physiatrists involved in the rehabilitation process, we aimed to apply the Levin NBRS-R instrument to our patients in a semistructured form using closed questions and an enriched explanations of the items on the basis of the Turkish Brief Psychiatric Rating Scale. ${ }^{[10]}$ The NBRS is a multidimensional and clinical-based assessment instrument which was developed by Levin ${ }^{[1]}$ and later revised by Levin to enhance its reliability and validity. ${ }^{[1]}$ In 2000 , Vanier et al. $^{[8]}$ conducted a validity and reliability study of the NBRS-R on 286 brain injured patients in 15 French hospitals. In 2001, the most recent revision form of NBRS was prepared and used to evaluate 392 TBI patients in the USA ${ }^{[9]}$ In addition to Western countries, the scale has also been demonstrated to be applicable to Chinese patients. ${ }^{[12]}$ To the best of our knowledge, this is the first study in Turkey to present a reproducible and reliable evaluation of neurobehavioral outcome measurement in brain injured patients.

\section{PATIENTS AND METHODS}

This cross-sectional, multi-center study investigated the inter-rater agreement of NBRS-R at various stages of recovery during hospitalization for TBI of patients suffering from symptoms that had a wide range of severity. Of the 51 patients initially enrolled, six were excluded from the study because they cooperated poorly during the interview session. A total of 45 participants (36 males, 9 females; mean age $31.1 \pm 13.0$ years; range 18 to 60 years) were recruited from four rehabilitation units (included in traumatic/hypoxic brain injury study group; 1 general hospital, 2 rehabilitation centers and 1 university hospital) between September 2013 and August 2014.

The participant inclusion criteria for the study were as follows: age between 13-65 years, abnormal computed tomography (CT) findings with any Glasgow Coma Scale $(\mathrm{GCS})^{[13]}$ (i.e., mild, ${ }^{[13-15]}$ moderate, ${ }^{[9-12]}$ and/or severe TBI,,$\left.^{[3-8]}\right)$ Turkish language skills, normal psychomotor development prior to TBI-related hospitalization, and adequate physical, mental and communication capabilities to cooperate and complete the NBRS-R test. Exclusion criteria included GCS score of 3 or under, unreactive pupils, unstable cardiopulmonary findings and previous history of neuropsychiatric disorders due to alcoholism, drug abuse or brain injury.

For this study, brain injuries were classified as mild, moderate or severe based primarily on the postresuscitation GCS score obtained in the intensive care unit. Minor head injury was defined as loss of consciousness for $\leq 30 \mathrm{~min}$, a GCS score of 13-15 upon hospital admission, no deterioration in GCS score to $<13$ and normal findings on cranial CT and neurological examinations. Moderate head injury was defined as a GCS score of 9-12 on admission with no further deterioration and severe brain injury as a GCS score of $<8$ for at least six hours on admission.

All patients had undergone a clinical examination and cranial CT scan. A comprehensive interview was also utilized to ascertain demographic and background information (i.e., age, sex, education duration, age at traumatic brain injury, marital status). Details of the injury or trauma were also recorded (i.e., etiology, duration of post-traumatic amnesia [PTA] and coma).

To ensure that patients were capable of undergoing the assessment and had reached a relatively stable level, patients with moderate and severe head injuries were examined three to six months after injury. The interviews were videotaped in each center and the videos were sent to the examiners at four different centers for independent ratings. The examiners were unable to identify patients based on the interviews. Thus, four independent ratings were obtained for each patient from the interviews. The examiners did not communicate with each other about their findings during or following the assessment.

The original NBRS is a multi-dimensional rating scale designed to assess the behavioral manifestations of brain injury. In a study of 101 patients who were heterogeneous in terms of the severity and chronicity of brain injury, Levin et al. ${ }^{[1]}$ demonstrated the sensitivity of NBRS in both of these patient variables. Revisions of NBRS have been developed in French (Montreal, Canada; Bordeaux, France) and English (Galveston, Texas). The most important changes integrated into the NBRS-R have been in the scoring range, which has been reduced from seven levels to four (absent, mild, moderate, severe) to increase inter-observer reliability. ${ }^{[8,11,14]}$ The scoring guide has also been 
expanded to include an interpretation for each level of each item. This interpretation is based on the impact of the deficits related to social skills and occupational outcomes. Furthermore, instead of 27 items used in NBRS, the NBRS-R consists of 29 items. Questions were created for each of the 29 items. Appropriate responses for each question were designed and scored in four levels as in the revised form.

To obtain uniform data, a semi-structured interview took place using a multidisciplinary approach (10 physiatrists, 1 psychiatrist, 1 neurologist, 1 psychologist). This approach was chosen based on recommendations for the completion of both the original and revised forms of NBRS, which included a brief test of alertness, orientation, expressive/receptive language functioning, review of post-concussion symptoms and emotional state, memory of recent events, motor skills, focused attention, attitude towards social environment (irritability, hostility, misinterpretation of others' actions, suspiciousness), capacity for self-insight, difficulty in planning and delayed recall of conceptual organization.

The NBRS-R form was independently translated into Turkish by a bilingual psychiatrist and three physiatrists. After comparing all the translations and making the necessary corrections, a new version of the tool with item explanations and closed questions was created. It was then translated into English in collaboration with a professional translator. The final Turkish version compliance with NBRS-R was accepted following a comparison of the meaning and format with the original English form. Permission was obtained from the authors (Levin et al. ${ }^{[1]}$ ) of NBRS-R to create and use the Turkish version of the scale and study the reliability of the revised scale (Appendix).

Patients from each center were evaluated by the same examiners who specialized in brain-injury. Prior to the study, three training sessions were held, during which the principal authors of the NBRS-R explained the instrument content and administration procedures. In addition, the authors discussed possible difficulties with interpretation and scoring with the support of videotaped administrations of NBRS-R on patients presenting various degrees of injury severity and neuropsychological deficits. Each of the three sessions was interspersed with practice administering the instrument by all evaluators. For patients who were well enough to undergo the full evaluation, the interview and brief cognitive tests comprising the NBRS-R were completed in approximately half an hour and were administered at the patient's bedside.
Data was collected at Dışkapı Yıldırım Beyazıt Training and Research Hospital (center 1) using a cross-sectional test-retest design.

The study was approved by the Ankara Dışkapı Yildırım Beyazıt Training and Research Hospital Ethics Committee. Before evaluation, the patients and where appropriate, the caregivers, were given verbal and written information about the nature of the study. Informed consent forms were signed upon admission to the trial. All procedures were conducted in accordance with the Helsinki Declarations of 2004.

\section{Statistical analysis}

Descriptive statistics were expressed in mean and standard deviation (SD) for continuous variables and as number (n) and/or percentage (\%) for nominal variables. Inter-rater reliability (chance-corrected agreement of four independent raters from four independent centers) was estimated using an intraclass correlation coefficient, based on two-way random effects model, ICCs with a $95 \%$ confidence interval as suggested in the literature. ${ }^{[15,16]}$ For ICC results, positive values ranging from 0 to 0.2 indicated poor agreement; 0.2 to 0.4 , fair agreement; 0.4 to 0.6 , moderate agreement; 0.6 to 0.8 , good agreement; and 0.8 to 1 , very good agreement according to Bland and Altman. ${ }^{[17]}$ Power of the study was performed by post-hoc power calculation. A sample size of 45 subjects with four observations per subject achieves $90 \%$ power to detect an intraclass correlation of 0.70000 under the alternative hypothesis when the intra-class correlation under the null hypothesis is 0.50000 using an F-test with a significance level of 0.05000 . All statistical analyses were performed using SPSS 13.0 statistical package (SPSS, Chicago, IL, USA). A $p$ value of $<0.05$ was considered statistically significant.

\section{RESULTS}

Most of the participants (75.6\%) had between 5-11 years of education and 55.5\% were married. The mean time interval from the occurrence of the head injury to assessment was $16.7 \pm 19.8$ days, most patients had injury in both hemispheres $(77.8 \%)$ and the etiology of the injury was traffic accident in $73.3 \%$ of the study group. The mean initial GCS score was 7.48 (range, 3-15), the mean initial PTA was 48.31 days (range, 1-150) and the mean duration of coma was 34.93 days (range, 1-91). The demographic characteristics and severity of the patient injuries are shown in Table 1. 
Table 1. Demographic characteristics and the severity of injuries of the patients in the study group

\begin{tabular}{|c|c|c|c|c|}
\hline Variables & $\mathrm{n}$ & $\%$ & Mean \pm SD & Range \\
\hline \multicolumn{5}{|l|}{ Sex } \\
\hline Male & 36 & 80 & & \\
\hline Female & 9 & 20 & & \\
\hline Age (year) & & & $31.1 \pm 13.0$ & $18-60$ \\
\hline \multicolumn{5}{|l|}{ Education } \\
\hline Student & 4 & 8.9 & & \\
\hline Elementary level (5 years) & 12 & 26.7 & & \\
\hline Intermediate level (8 years) & 8 & 17.8 & & \\
\hline Secondary level (11 years) & 14 & 31.1 & & \\
\hline Post-secondary level (>11 years) & 7 & 15.6 & & \\
\hline \multicolumn{5}{|l|}{ Marital status } \\
\hline Married & 20 & 44.4 & & \\
\hline Single & 25 & 55.6 & & \\
\hline Injury test interval (months) $(\mathrm{n}=43)$ & & & $16.7 \pm 19.8$ & $3-60$ \\
\hline \multicolumn{5}{|l|}{ Mechanism of injury } \\
\hline Traffic accident (inside the vehicle) & 19 & 42.2 & & \\
\hline Traffic accident (outside the vehicle) & 14 & 31.1 & & \\
\hline Fall from height & 4 & 8.9 & & \\
\hline Work accident & 3 & 6.7 & & \\
\hline Others & 5 & 11.1 & & \\
\hline \multicolumn{5}{|l|}{ Type of injury } \\
\hline Bilateral hemisphere & 35 & 77.8 & & \\
\hline Right hemisphere & 4 & 8.9 & & \\
\hline Left hemisphere & 6 & 13.3 & & \\
\hline Initial Glasgow coma scale $(\mathrm{n}=25)$ & & & $7.5 \pm 3.3$ & $3-15$ \\
\hline Duration of coma (days) $(\mathrm{n}=42)$ & & & $34.9 \pm 28.6$ & $1-91$ \\
\hline Initial posttraumatic amnesia (days) $(n=29)$ & & & $48.3 \pm 41.2$ & $1-150$ \\
\hline
\end{tabular}

Four different interviewers from four centers evaluated all the patients $(n=45)$ and the mean scores for each NBRS-R item are given in Table 2. The ratio of questions which were completely answered or evaluated differed between the study centers, as 43/45 (95.6\%), 36/45 (80.0\%), 39/45 (86.7\%) and 40/45 $(88.9 \%)$, respectively. The data of the whole sample (45 participants) was collected at Dışkapı Yıldırım Beyazit Training and Research Hospital (center 1 as mentioned above) and was analyzed and discussed to determine the degree of reliability.

In the measurements performed with ICC, the values varied from 0.501 to 0.962 , suggesting satisfactory stability and the reliability of the items ranged from moderate to very good. Twenty-two items showed very good agreement, five items showed good agreement and two items (irritability and excitement) showed moderate agreement (0.501 and 0.529). None of the items showed poor or fair agreement. The mean percentage of agreement among all 29 items was $87.0 \%$ (Table 3 ).

\section{DISCUSSION}

In this study, a total of 45 patients were administered the NBRS-R. Almost all the patients were evaluated during inpatient rehabilitation. In 36 of 45 patients, initial GCS and PTA times revealed serious TBI. The ratio of the questions which were completely answered or evaluated differed between $80.0 \%$ and 95.6\% in the four centers, which may have been the result of a variety of factors. The most important patient-related factor playing a role in the ratio of unanswered questions was that the number of items which were unable to be evaluated was naturally high in patients with difficulty in verbal expression and impaired articulation. However, in one case with good perception but complete motor aphasia, all the information about the patient was gained and how the patient perceived all the given orders was assessed with the help of gestures and a cell phone. This had a positive effect on patient-physician interaction.

In this study, the inter-rater correlation coefficient between the interviewers ranged from 0.501 to 0.962 . The mean percentage of agreement among all 29 items was $87.0 \%$. There was a higher inter-rater correlation compared to previous studies. The higher inter-rater correlation in this study may be the result of the detailed descriptions of items including psychiatric questions, which represents a rigorous aspect of this study. 
Table 2. Four different interviewers from four centres evaluated all the patients $(n=45)$ and the mean scores for each Neurobehavioral Rating Scale-Revised item

\begin{tabular}{|c|c|c|c|c|c|c|c|c|c|c|c|c|}
\hline & \multicolumn{3}{|c|}{ Center 1} & \multicolumn{3}{|c|}{ Center 2} & \multicolumn{3}{|c|}{ Center 3} & \multicolumn{3}{|c|}{ Center 4} \\
\hline & $\mathrm{n}$ & Median & Range & $\mathrm{n}$ & Median & Range & $\mathrm{n}$ & Median & Range & $\mathrm{n}$ & Median & Range \\
\hline \multicolumn{13}{|l|}{ Q1. Lack of attention/reduced } \\
\hline $\begin{array}{l}\text { alertness } \\
\text { Hortion }\end{array}$ & 45 & 1.00 & $1-3$ & 45 & 1.00 & - & 45 & 1.00 & - & 45 & 1.00 & $1-2$ \\
\hline Q2. Hyperactivity/agitation & 45 & 1.00 & $1-3$ & 45 & 1.00 & $1-3$ & 45 & 1.00 & $1-2$ & 45 & 1.00 & $1-3$ \\
\hline Q3. Disorientation & 45 & 2.00 & $1-4$ & 45 & 2.00 & $1-4$ & 45 & 2.00 & $1-4$ & 45 & 2.00 & $1-4$ \\
\hline Q4. Attention deficit & 44 & 1.00 & $1-4$ & 45 & 1.00 & $1-4$ & 43 & 1.00 & $1-4$ & 45 & 1.00 & $1-4$ \\
\hline Q5. Articulation disorder & 44 & 1.00 & $1-4$ & 45 & 1.00 & $1-4$ & 43 & 1.00 & $1-4$ & 45 & 1.00 & $1-4$ \\
\hline \multicolumn{13}{|l|}{ Q6. Difficulty in verbal } \\
\hline expression & 44 & 1.00 & $1-4$ & 45 & 1.00 & $1-4$ & 44 & 1.00 & $1-4$ & 45 & 1.00 & $1-4$ \\
\hline \multicolumn{13}{|l|}{ Q7. Decrease in verbal } \\
\hline comprehensibility & 45 & 1.00 & $1-3$ & 44 & 1.00 & $1-3$ & 43 & 1.00 & $1-4$ & 43 & 1.00 & $1-3$ \\
\hline Q8. Memory deficit & 44 & 2.00 & $1-4$ & 36 & 2.00 & $1-4$ & 43 & 2.00 & $1-4$ & 40 & 2.00 & $1-4$ \\
\hline Q9. Motor retardation & 45 & 1.00 & $1-4$ & 45 & 1.00 & $1-4$ & 43 & 2.00 & $1-4$ & 44 & 1.00 & $1-4$ \\
\hline Q10. Somatic symptom disorder & 44 & 1.00 & $1-4$ & 45 & 2.00 & $1-4$ & 44 & 2.00 & $1-4$ & 44 & 2.00 & $1-4$ \\
\hline \multicolumn{13}{|l|}{ Q11. Inaccurate insight and } \\
\hline self-appraisal & 44 & 1.00 & $1-4$ & 45 & 1.00 & $1-4$ & 42 & 1.00 & $1-4$ & 44 & 1.00 & $1-4$ \\
\hline Q12. Hallucination & 44 & 1.00 & $1-4$ & 43 & 1.00 & $1-4$ & 39 & 1.00 & $1-4$ & 43 & 1.00 & $1-4$ \\
\hline Q13. Bizarre thought content & 44 & 1.00 & $1-3$ & 45 & 1.00 & $1-4$ & 39 & 1.00 & $1-3$ & 44 & 1.00 & $1-4$ \\
\hline Q14. Anxiety & 44 & 1.50 & $1-4$ & 44 & 1.00 & $1-4$ & 42 & 1.00 & $1-3$ & 43 & 2.00 & $1-4$ \\
\hline Q15. Depressed mood & 44 & 1.00 & $1-4$ & 45 & 1.00 & $1-4$ & 43 & 1.00 & $1-3$ & 44 & 1.00 & $1-3$ \\
\hline Q16. Guilt & 43 & 1.00 & $1-3$ & 43 & 1.00 & $1-3$ & 40 & 1.00 & $1-3$ & 43 & 1.00 & $1-3$ \\
\hline Q17. Mood dysregulation & 45 & 1.00 & $1-3$ & 45 & 1.00 & $1-4$ & 43 & 1.00 & $1-4$ & 45 & 1.00 & $1-4$ \\
\hline Q18. Mood regulation & 45 & 1.00 & $1-3$ & 45 & 1.00 & $1-3$ & 43 & 1.00 & $1-3$ & 45 & 1.00 & $1-4$ \\
\hline Q19. Irritability & 45 & 1.00 & $1-3$ & 45 & 1.00 & $1-3$ & 44 & 2.00 & $1-4$ & 45 & 2.00 & $1-2$ \\
\hline Q20. Decrease in self-control & 44 & 1.00 & $1-3$ & 45 & 1.00 & $1-3$ & 44 & 2.00 & $1-3$ & 44 & 2.00 & $1-3$ \\
\hline Q21. Excitement & 44 & 1.00 & $1-3$ & 45 & 1.00 & $1-3$ & 43 & 1.00 & $1-3$ & 45 & 1.00 & $1-2$ \\
\hline Q22. Aggression & 44 & 1.00 & $1-2$ & 45 & 1.00 & $1-3$ & 42 & 1.00 & $1-2$ & 45 & 1.00 & $1-3$ \\
\hline Q23. Suspiciousness & 44 & 1.00 & $1-4$ & 44 & 1.00 & $1-4$ & 42 & 1.00 & $1-4$ & 43 & 1.00 & $1-4$ \\
\hline Q24. Emotional withdrawal & 43 & 1.00 & $1-3$ & 42 & 1.00 & $1-3$ & 41 & 1.00 & $0-3$ & 44 & 1.00 & $1-4$ \\
\hline Q25 Conceptual disorganization & 43 & 1.00 & $1-4$ & 45 & 1.00 & $1-4$ & 41 & 2.00 & $1-4$ & 44 & 1.00 & $1-4$ \\
\hline Q26 Mental flexibility deficit & 44 & 1.00 & $1-4$ & 43 & 2.00 & $1-4$ & 43 & 2.00 & $0-4$ & 44 & 1.00 & $1-4$ \\
\hline Q27. Difficulty in planning & 44 & 1.00 & $1-4$ & 44 & 1.00 & $1-4$ & 42 & 2.00 & $1-4$ & 43 & 1.00 & $1-4$ \\
\hline \multicolumn{13}{|l|}{ Q28. Decrease in starting } \\
\hline a task or motivation & 44 & 1.00 & $1-4$ & 44 & 1.00 & $1-4$ & 42 & 1.00 & $1-4$ & 44 & 1.00 & $1-4$ \\
\hline \multicolumn{13}{|l|}{ Q29. Tendency to rapid mental } \\
\hline fatigue & 45 & 1.00 & $1-4$ & 44 & 1.00 & $1-3$ & 40 & 1.00 & $1-4$ & 44 & 1.00 & $1-3$ \\
\hline
\end{tabular}

SD: Standard deviation; Q: Question.

From the standpoint of both better planning, and an intra- and interdisciplinary common language, the utilization of neuropsychological tests would enable comprehensive rehabilitation and aid studies which aim to make progress in these topics. As a rating instrument for behavioral disorders, the NBRS scale has considerable importance in the field of rehabilitation. ${ }^{[18]}$

It is accepted that in severe TBI patients' dysfunction usually depends on cognitive deficits rather than emotional disorders or physical impairments, and NBRS-R is an important evaluation tool for identifying neurobehavioral dysfunction for this reason, NBRS-R was selected for the patient population of this study. ${ }^{[19]}$
In our clinics, there is an increasing annual incidence of brain injured patients. Therefore, it is important for physiatrists to develop a reproducible and reliable assessment system for neurobehavioral disorders.

The NBRS-R, configured in Turkish, was applied mostly to patients with moderate and serious TBI. In this study, the test time after injury varied by a wide margin and NBRS-S revealed that symptom profiles also varied according to different time points at which the test was performed, which may also include the recovery that developed with time.

In a revision study about NBRS performed by McCauley et al. ${ }^{[9]}$ in 2001 of 392 patients with head trauma, 105 died within six months and 77 of the 
Table 3. Inter-rater reliability of the Turkish version of the Neurobehavioral Rating Scale-revised items with factor structure

\begin{tabular}{lccc}
\hline & ICC & $(95 \% \mathrm{CI})$ & Significance \\
\hline Q1. Lack of attention/reduced alertness & 0.923 & $(0.878-0.954)$ & $<0.001$ \\
Q2. Hyperactivity/agitation & 0.808 & $(0.697-0.886)$ & $<0.001$ \\
Q3. Disorientation & 0.939 & $(0.904-0.964)$ & $<0.001$ \\
Q4. Attention deficit & 0.914 & $(0.864-0.950)$ & $<0.001$ \\
Q5. Articulation disorder & 0.835 & $(0.729-0.905)$ & $<0.001$ \\
Q6. Difficulty in verbal expression & 0.961 & $(0.938-0.977)$ & $<0.001$ \\
Q7. Decrease in verbal comprehensibility & 0.951 & $(0.922-0.971)$ & $<0.001$ \\
Q8. Memory deficit & 0.942 & $(0.904-0.968)$ & $<0.001$ \\
Q9. Motor retardation & 0.822 & $(0.708-0.897)$ & $<0.001$ \\
Q10. Somatic symptom disorder & 0.796 & $(0.672-0.880)$ & $<0.001$ \\
Q11. Inaccurate insight and self-appraisal & 0.884 & $(0.813-0.933)$ & $<0.001$ \\
Q12. Hallucination & 0.898 & $(0.834-0.942)$ & $<0.001$ \\
Q13. Bizarre thought content & 0.728 & $(0.556-0.844)$ & $<0.001$ \\
Q14. Anxiety & 0.865 & $(0.783-0.922)$ & $<0.001$ \\
Q15. Depressed mood & 0.928 & $(0.882-0.958)$ & $<0.001$ \\
Q16. Guilt & 0.881 & $(0.805-0.932)$ & $<0.001$ \\
Q17. Mood dysregulation & 0.786 & $(0.656-0.875)$ & $<0.001$ \\
Q18. Mood regulation & 0.659 & $(0.458-0.798)$ & $<0.001$ \\
Q19. Irritability & 0.501 & $(0.212-0.703)$ & 0.001 \\
Q20. Decrease in self-control & 0.805 & $(0.690-0.885)$ & $<0.001$ \\
Q21. Excitement & 0.529 & $(0.245-0.725)$ & 0.001 \\
Q22. Aggression & 0.772 & $(0.621-0.869)$ & $<0.001$ \\
Q23. Suspiciousness & 0.962 & $(0.939-0.978)$ & $<0.001$ \\
Q24. Emotional withdrawal & 0.841 & $(0.740-0.910)$ & $<0.001$ \\
Q25. Conceptual disorganization & 0.893 & $(0.807-0.942)$ & $<0.001$ \\
Q26. Mental flexibility deficit & 0.922 & $(0.872-0.955)$ & $<0.001$ \\
Q27. Difficulty in planning & 0.854 & $(0.759-0.917)$ & $<0.001$ \\
Q28. Decrease in starting a task or motivation & 0.923 & $(0.877-0.955)$ & $<0.001$ \\
Q29. Tendency to rapid mental fatigue & 0.841 & $(0.7370 .910)$ & $<0.001$ \\
\hline ICC. & & & \\
\hline
\end{tabular}

ICC: Intraclass correlation coefficient; CI: Confidence interval; Q: Question.

remaining 287 patients $(26.8 \%)$ were unable to complete the NBRS revision study for various reasons. One of the main reasons was that although the patients were conscious, their condition was so poor that they were either unable to start or complete the evaluation. Other reasons included being in a vegetative state, rejecting the test and language problems. ${ }^{[9]}$

In the current study, $11.8 \%$ of participants were unable to complete the test fully. It is obvious that the state of consciousness and patient cooperation are important factors to be able to perform this evaluation. Among the items of NBRS-R, the questions measuring awareness, difficulty in verbal expression and impaired articulation may be the best indicators of whether the patient will be able to complete the test or not. Moderate and serious impairments of these items cause difficulty in the evaluation of emotional parameters in particular.

In the Turkish health system, there is no specifically designed model for TBI. Patients either go to residential or public based rehabilitation programs upon discharge or any brain injury support groups. With these shortcomings in both organization and standards, difficulties arise in patient recruitment and a registry system for scientific research. As a result, this study included a limited number of patients. The most important part of the rehabilitation program in TBI is given by Physical Medicine and Rehabilitation clinics in certain centers that deal with this topic nationwide. Hospitals where the study was conducted were the most commonly preferred centers in this regard.

In conclusion, this study can be considered pioneering in both clinical practice and research in that it focused on the screening of neurobehavioral symptoms by physiatrists using a general neurobehavioral scale in patients with moderateserious TBI. To provide greater clarity for researchers who will use this version, a change is recommended in the questioning of only two items that have moderate compliance. 


\section{Declaration of conflicting interests}

The authors declared no conflicts of interest with respect to the authorship and/or publication of this article.

\section{Funding}

The authors received no financial support for the research and/or authorship of this article.

\section{REFERENCES}

1. Levin HS, High WM, Goethe KE, Sisson RA, Overall JE, Rhoades HM, et al. The neurobehavioural rating scale: assessment of the behavioural sequelae of head injury by the clinician. J Neurol Neurosurg Psychiatry 1987;50:183-93.

2. Dikmen S, Temkin N, McLean A, Wyler A, Machamer J. Memory and head injury severity. J Neurol Neurosurg Psychiatry 1987;50:1613-8.

3. Brenner LA, Ivins BJ, Schwab K, Warden D, Nelson LA, Jaffee $M$, et al. Traumatic brain injury, posttraumatic stress disorder, and postconcussive symptom reporting among troops returning from iraq. J Head Trauma Rehabil 2010;25:307-12.

4. Draper K, Ponsford J. Cognitive functioning ten years following traumatic brain injury and rehabilitation. Neuropsychology 2008;22:618-25.

5. Bazarian JJ, Cernak I, Noble-Haeusslein L, Potolicchio S, Temkin N. Long-term neurologic outcomes after traumatic brain injury. J Head Trauma Rehabil 2009;24:439-51.

6. Bigler ED. Neuropsychology and clinical neuroscience of persistent post-concussive syndrome. J Int Neuropsychol Soc 2008;14:1-22.

7. Castaño Monsalve B, Laxe S, Bernabeu Guitart M, Vilarrasa $\mathrm{AB}$, Quemada JI. Behavioral scales used in severe and moderate traumatic brain injury. NeuroRehabilitation 2014;35:67-76.

8. Vanier M, Mazaux JM, Lambert J, Dassa C, Levin HS. Assessment of neuropsychologic impairments after head injury: interrater reliability and factorial and criterion validity of the Neurobehavioral Rating Scale-Revised. Arch
Phys Med Rehabil 2000;81:796-806.

9. McCauley SR, Levin HS, Vanier M, Mazaux JM, Boake C, Goldfader PR, et al. The neurobehavioural rating scalerevised: sensitivity and validity in closed head injury assessment. J Neurol Neurosurg Psychiatry 2001;71:643-51.

10. Soykan C. Institutional differences and case typicality as related to diagnosis system severity, prognosis and treatment. Master Thesis, Middle East Technical University, Ankara, Turkey; 1989.

11. Levin HS, Mazaux JM, Vanier M, Dartigues JF, Giroire JM, Daverat $\mathrm{P}$, et al. Evaluation des troubles neuropsychologiques et comportementaux des traumatisés crâniens par le clinicien: proposition d'une échelle neurocomportementale et premiers résultats de sa version française. Annales de Réadaptation et de Médecinephysique 1990;33:35-40.

12. Chiu WT, Lin WY, Lin LS, Hung CC, Shih CJ. Neurobehavioral manifestations following closed head injury. J Formos Med Assoc 1993;92:255-62.

13. Teasdale G, Jennett B. Assessment of coma and impaired consciousness. A practical scale. Lancet 1974;2:81-4.

14. Soury S, Mazaux JM, Lambert J, De Seze M, Joseph PA, Lozes-Boudillon $\mathrm{S}$, et al. The neurobehavioral rating scalerevised: assessment of concurrent validity. Ann Readapt Med Phys 2005;48:61-70. [Abstract]

15. Shrout PE. Measurement reliability and agreement in psychiatry. Stat Methods Med Res 1998;7:301-17.

16. Shrout PE, Fleiss JL. Intraclass correlations: uses in assessing rater reliability. Psychol Bull 1979;86:420-8.

17. Bland JM, Altman DG. Statistical methods for assessing agreement between two methods of clinical measurement. Lancet 1986;1:307-10.

18. Castaño Monsalve B, Laxe S, Bernabeu Guitart M, Vilarrasa $A B$, Quemada JI. Behavioral scales used in severe and moderate traumatic brain injury. NeuroRehabilitation 2014;35:67-76.

19. Rapoport M, McCauley S, Levin H, Song J, Feinstein A. The role of injury severity in neurobehavioral outcome 3 months after traumatic brain injury. Neuropsychiatry Neuropsychol Behav Neurol 2002;15:123-32. 


\begin{tabular}{|c|c|}
\hline \multicolumn{2}{|l|}{ APPENDIX } \\
\hline $\begin{array}{l}\text { 1- Lack of attention/reduced alertness } \\
\text { He/she fails to keep his/her attention, becomes distracted easily, fails to pay } \\
\text { attention to the characteristics of environment, has difficulty in focusing his/ } \\
\text { her attention. Reduced alertness. }\end{array}$ & $\begin{array}{l}\text { None: Conscious, cooperative } \\
\text { Mild: Intermittent disintegration in consciousness and cooperation } \\
\text { Moderate: Moderate difficulty in consciousness and cooperation } \\
\text { Severe: Absent cooperation }\end{array}$ \\
\hline $\begin{array}{l}\text { 2- Hyperactivity and agitation (observational) } \\
\text { Motor symptoms of hyperactivity (e.g. kicking, walking around, uneasiness, } \\
\text { talking too much) }\end{array}$ & $\begin{array}{l}\text { None: No increase in mobility. } \\
\text { Mild: He/she sometimes has physical agitation during the day. He/she can } \\
\text { control himself/herself. } \\
\text { Moderate: He/she is frequently agitated, additional measure is required. } \\
\text { Severe: } \mathrm{He} / \text { she gets so agitated that he/she can hurt himself/herself or others. } \\
\text { Additional medication or measure should be taken. }\end{array}$ \\
\hline $\begin{array}{l}\text { 3- Disorientation } \\
\text { Confusion or lack of appropriate behavior for person, place or time } \\
\text { 1. What year is it now? } \\
\text { 2. What season is it now? } \\
\text { 3. What month is it now? } \\
\text { 4. What day is it? }\end{array}$ & $\begin{array}{l}\text { None: Correct answer to all questions } \\
\text { Mild: Correct answer to } 3 \text { questions } \\
\text { Moderate: Correct answer to } 2 \text { questions } \\
\text { Severe: Correct answer to } 1 \text { question }\end{array}$ \\
\hline $\begin{array}{l}\text { 4- Attention deficit (unavailable in } 27 \text {-form) } \\
\text { Question: Say the days of the week in reverse order. What day is it after Sunday, } \\
\text { Saturday? (For example; Sunday, Saturday, Friday: } 2 \text { correct answers) }\end{array}$ & $\begin{array}{l}\text { None: } 5 \text { Correct answers } \\
\text { Mild: } 4 \text { Correct answers } \\
\text { Moderate: } 3 \text { correct answers } \\
\text { Severe: } 2 \text { correct answers }\end{array}$ \\
\hline $\begin{array}{l}\text { 5- Articulation disorder } \\
\text { Wrong articulation, slurring or shifting the letters (grade is independent of the } \\
\text { content of language) } \\
\text { Question: Repetition of 1,2, } 3 \text { or } 4 \text { syllable word is requested. }\end{array}$ & $\begin{array}{l}\text { None: Correct answer to } 4 \text { syllable word } \\
\text { Mild: Correct answer to } 3 \text { syllable word } \\
\text { Moderate: Correct answer to } 2 \text { syllable word } \\
\text { Severe: Correct answer to } 1 \text { syllable word }\end{array}$ \\
\hline $\begin{array}{l}\text { 6- Difficulty in verbal expression } \\
\text { Difficulty in finding word, anomie, hesitation in speaking, speaking with bad } \\
\text { grammar, circumstantiality. } \\
\text { The following questions may be asked. Free speaking for } 1-2 \text { minutes is } \\
\text { permitted during interview. } \\
\text { Questions: } \\
\text { 1. Where were you born? } \\
\text { 2. Where do you live? } \\
\text { 3. What is the name of your mother and father? } \\
\text { 4. What is your brother's or sister's name? } \\
\text { 5. What do you use for eating soup? } \\
\text { 6. What do you wear on your feet? } \\
\text { 7. What do you use to comb your hair? } \\
\text { 8. What do you use for writing? }\end{array}$ & $\begin{array}{l}\text { None: } \mathrm{He} / \text { she can answer 7-8 questions. } \\
\text { Mild: } \mathrm{He} / \mathrm{she} \text { can answer 5-6 questions. } \\
\text { Moderate: } \mathrm{He} / \mathrm{she} \text { can answer 3-4 questions. } \\
\text { Severe: } \mathrm{He} / \mathrm{she} \text { can answer 1-2 question(s). }\end{array}$ \\
\hline $\begin{array}{l}\text { 7- Decrease in verbal comprehensibility } \\
\text { Lack of comprehension, difficulty in comprehending simple or complex } \\
\text { questions. } \\
\text { Questions: } \\
\text { 1. Take the pencil which is on the table. } \\
\text { 2. Take the pencil which is on the table with your left hand. } \\
\text { 3. Take the pencil which is on the table with your right hand and pass it } \\
\text { to your left hand. } \\
\text { 4. Take the pencil which is on the table with your right hand, pass it to your } \\
\text { left hand and put it again on the table. }\end{array}$ & $\begin{array}{l}\text { None: correct respond to } 4 \text { commands } \\
\text { Mild: correct respond to } 3 \text { commands } \\
\text { Moderate: correct respond to } 2 \text { commands } \\
\text { Severe: correct respond to } 1 \text { command }\end{array}$ \\
\hline $\begin{array}{l}\text { 8- Memory deficit } \\
\text { Difficulty in learning new information, rapid forgetting of recent events, } \\
\text { immediate recall or counting up may be preserved. } \\
\text { Question: Names of } 4 \text { unrelated objects such as table, flag, dress, watch are } \\
\text { given. Repeat is requested. }\end{array}$ & $\begin{array}{l}\text { None: } \mathrm{He} / \text { she repeats the names of } 4 \text { objects. } \\
\text { Mild: } \mathrm{He} / \mathrm{she} \text { repeats the names of } 3 \text { objects. } \\
\text { Moderate: He/she repeats the names of } 2 \text { objects. } \\
\text { Severe: } \mathrm{He} / \text { she repeats the name of } 1 \text { object or cannot repeat. }\end{array}$ \\
\hline $\begin{array}{l}\text { 9- Motor retardation } \\
\text { Slowed movement or speech (with the exception of primary loss of strength) } \\
\text { It is observed while performing commands during interview. }\end{array}$ & $\begin{array}{l}\text { None: } \mathrm{He} / \mathrm{she} \text { can perform within desired time. } \\
\text { Mild: } \mathrm{He} / \mathrm{she} \text { can perform the movement, but he/she completes within a longer } \\
\text { time than expected. } \\
\text { Moderate: He/she can complete the movement with physical assistance or } \\
\text { verbal motivation. } \\
\text { Severe: The movement cannot be completed. }\end{array}$ \\
\hline $\begin{array}{l}\text { 10- Somatic symptom disorder } \\
\text { He/she complains of somatic symptoms (headache, dizziness, blurred vision) } \\
\text { and his/her general physical health complicates the issue. } \\
\text { Question: Do you have any worries about your physical health? Do you } \\
\text { frequently go to doctor? How does this affect your life? }\end{array}$ & $\begin{array}{l}\text { None } \\
\text { Mild: There are somatic complaints that he/she tends to keep to himself/herself } \\
\text { or say to close circle of friends. } \\
\text { Moderate: He/she often expresses his/her complaints about current illness. } \\
\text { Severe: His/her daily life and performance deteriorated due to somatic } \\
\text { complaints. }\end{array}$ \\
\hline
\end{tabular}




\section{1- Inaccurate insight and self-appraisal \\ Weak insight; inappropriate opinions for self-appraisal, overestimating his/ her own capabilities or fail to realize personality changes, low gradation of personality changes by clinicians and family members. \\ Weak insight, overestimation, personality changes. Information is obtained from his/her relatives.}

\section{2- Hallucination}

Perception of stimulus such as light, sound in the absence of any stimulus in the environment.

Are there any sounds or images or situations that are noticed only by you but not noticed by those who are around you?

\section{3- Bizarre thought content-observational (will be evaluated during test} period)

Bizarre thought content.

Unlike almost everyone's beliefs, even if there are evidences, these are false personal beliefs arising from the wrong interpretation of external reality and held with strong conviction.

Have you any thoughts which seem strange for your friends and in which they have difficulty in believing

\section{4- Anxiety}

Worry, fear, strong concerns for current and future time.

Question: Have you ever felt anxious, worried or apprehension? If so, what about was it? Did you experience any symptoms such as palpitation, sweating, difficulty in breathing?

\section{5- Depressed mood}

Depressive affect, pain sorrow, pessimism, unhappiness

Question: How are you today, how do you feel?

\section{6- Guilt}

Self-accusation, feeling ashamed, looking back in regret.

Question: Do you feel guilty about anything? Do you tend to blame yourself for what happened? Do you feel ashamed for what you did?

\section{7-Mood dysregulation (observational, will be evaluated during the interview)}

Rapid change in mood

There are severe emotional disturbances and confusions in which all mixed emotions or emotional changes from one uncontainable emotion to another coexist.

18- Mood regulation (observational, will be evaluated during the interview) Decreased mood, decrease in the severity of normal emotions, boringness

There are significant decreases in expressions and gestures (face, voice, gesticulation). (If you are not sure, you can observe his/her response to a joke)

\section{9- Irritability}

(observational or will be evaluated during the interview)

Tension. Increased tension reflects in his/her face and posture. Excessive extremity and body movements may not accompany.

20- Decrease in self-control (observational or information obtained from relatives)

Socially inappropriate behavior. May have aggressive or sexual content. Outbursts of anger occur.

It means that person cannot properly express his/her behaviors, feelings and impulses.

\section{1- Excitement}

Excitement, excitability. Increased intensity in face, voice, gestures; increased emotional reactions against the interviewer or conversation, increased emotional tone.

Question: How do you feel? (or observational)
None: No change.

Mild: He/she exhibits behaviors and conversations inconsistent with his/her past personality.

Moderate: There are often inappropriate behaviors and conversations, lack of insight, behavioral changes.

Severe: $\mathrm{He} / \mathrm{she}$ is not aware of his/her condition. There is an obvious behavioral change.

None: No hallucination

Mild: There are visual and auditory hallucinations while he/she is fully awake.

His/her performance (functioning) is good.

Moderate: There are visual, gustatory, olfactory, tactile hallucinations.

Performance (functioning) is deteriorated to some extent. Severe: There are hallucinations. He/she is not aware of himself/herself.

None: Appropriate answers are given to the questions during interview.

Mild: $\mathrm{He} /$ she calls attention to relaxation in associations. He/she digresses but completes the interview. There may be unusual beliefs in thought content but these are not at a delusional level.

Moderate: There are unusual beliefs in thought content. These are at delusional level.

Severe: Unusual beliefs in thought content at delusional level, many functioning areas are deteriorated due to the delusion.

\section{None: No anxiety.}

Mild: He/she expresses his/her feelings of anxiety. His/her daily life is not affected.

Moderate: He/she feels anxious all day long. Autonomic symptoms rarely occur. Severe: His/her functioning is deteriorated due to severe anxiety. Additional medication may be required.

None: No depression

Mild: He/she feels depressed but he/she thinks that he/she can overcome it. Moderate: He/she feels upset in most part of the day. His/her functioning is deteriorated to some extent.

Severe: He/she permanently feels upset almost every day. He/she has suicidal thoughts. His/her functioning is deteriorated.

None: $\mathrm{He} /$ she does not feel guilty about anything

Mild: He/she feels guilty. He/she is abstracted, but he/she can be distracted.

Moderate: He/she feels guilty. He/she is abstracted and his/her functioning is deteriorated. He/she has difficulty in directing his/her attention to another matter.

Severe: He/she blames himself/herself unjustifiably and disproportionately at a delusional level.

None: No signs of any change in emotions during the interview.

Mild: Emotional fluctuation rarely occurs but it does not affect the interview.

Moderate: Frequent emotional changes during the interview, but the interview can continue.

Severe: There is an emotional fluctuation that blocks the interview.

None: No sign of mood regulation during the interview.

Mild: Emotional range is narrow, his/her voice is slightly monotonous.

Moderate: There is a significant narrowing in emotional range. His/her voice is monotonous. Spontaneous movements are decreased.

Severe: Stable facial expression, mechanical gestures and speech. No emotional expressiveness.

None: No signs of irritability

Mild: There are wriggling movements such as hand rubbing, swinging his/ her feet.

Moderate: One or several frequent motor tension signs.

Severe: One or several permanent motor tension signs

None: No decrease in self-control (swearing, declamation)

Mild: Occasional verbal burst of anger (aggressive or with sexual content) during the day. He/she tries to control himself/herself.

Moderate: Frequent verbal and behavioral bursts of anger during the day.

Severe: Bursts of anger are frequent, affect the treatment. Verbal or behavioral outbursts are severe. No awareness.

None: No excitement (increase in speech, excessive cheerfulness)

Mild: Doubtful, light, temporarily increased gestures, refreshment in voice Moderate: Increased emotional intensity, a little cluttering, increased voice and gestures

Severe: Certain, permanent increase in emotional intensity. Difficulty in continuation of the treatment. 


\begin{tabular}{|c|c|}
\hline $\begin{array}{l}\text { 22- Aggression } \\
\text { Hostility, unease, quarrelsomeness, despising contravention } \\
\text { Question: Have you ever shouted at someone in a way that was physical or } \\
\text { have you ever wanted to kick someone or something? (or observational) }\end{array}$ & $\begin{array}{l}\text { None: No aggression (committing physical violence) } \\
\text { Mild: Uneasy, perturbed. He/she tries to keep calm. } \\
\text { Moderate: He/she is occasionally frustrated. He/she sometimes shouts at } \\
\text { someone. } \\
\text { Severe: Extremely angry, frustrated. He/she has reactions such as threatening } \\
\text { and throwing things. }\end{array}$ \\
\hline $\begin{array}{l}\text { 23- Suspiciousness (mistrustfulness) } \\
\text { Doubt, suspicion, thinking that others have bad intentions and purposes } \\
\text { including discrimination. } \\
\text { Question: Have you ever thought that others have bad thoughts about you or } \\
\text { try to hurt you? Do you feel that you are in danger? Does anyone try to give } \\
\text { you hard times or hurt your feelings? }\end{array}$ & $\begin{array}{l}\text { None: Nobody tries to hurt him/her } \\
\text { Mild: There are doubts, but he/she is not abstracted. } \\
\text { Moderate: He/she is abstracted due to doubts. His/her functioning is affected } \\
\text { to some extent. } \\
\text { Severe: At delusional level. He/she tends to reveal delusions or behave accord- } \\
\text { ingly. }\end{array}$ \\
\hline $\begin{array}{l}\text { 24- Emotional withdrawal (observational) } \\
\text { Spontaneous miscommunication, isolation, lack of communication with } \\
\text { others } \\
\text { Ability to make emotional contact during the interview. }\end{array}$ & $\begin{array}{l}\text { None: No withdrawal. He/she communicates with the others. } \\
\text { Mild: Failure to respond in communication. If someone steps up, he/she } \\
\text { responds. } \\
\text { Moderate: He/she does not make an eye contact. Rare emotional } \\
\text { communication. } \\
\text { Severe: No emotional communication. He/she shortly answers the questions } \\
\text { (such as yes or no) }\end{array}$ \\
\hline $\begin{array}{l}\text { 25- Conceptual disorganization (observational) } \\
\text { Thinking process is confused, irregular, out of order. Indirect social } \\
\text { relationship, perseverance } \\
\text { Question: What did you do today? }\end{array}$ & $\begin{array}{l}\text { None: Patient can properly express what he/she did. } \\
\text { Mild: Circumstantiality. He/she digresses but reaches to conclusion. } \\
\text { Moderate: Difficulty in comprehending the subject. He/she mostly changes } \\
\text { the subject. } \\
\text { Severe: Incomprehensible speech. Irrelevant sentences in the speech. }\end{array}$ \\
\hline $\begin{array}{l}\text { 26- Mental flexibility deficit (unavailable in } 27 \text {-form) } \\
\text { Question: Penny saved is a penny earned. What does it mean? }\end{array}$ & $\begin{array}{l}\text { None: He/she knows that it is about saving money. } \\
\text { Mild: Slow response. He/she cannot form a proper sentence, but he/she can } \\
\text { reach the main conclusion. } \\
\text { Moderate: He/she needs clues to answer. } \\
\text { Severe: Irrelevant answers or no answer. }\end{array}$ \\
\hline $\begin{array}{l}\text { 27- Difficulty in planning } \\
\text { Non-realistic goals, future planning is weak, ignoring the necessary will. } \\
\text { Question: "You come home at night. What will you do chronologically? } \\
\text { - Open the door with a key } \\
\text { - Turn on the light } \\
\text { - Close the door } \\
\text { - Bolt the door }\end{array}$ & $\begin{array}{l}\text { None: } \mathrm{He} / \mathrm{she} \text { can put } 4 \text { activities in order. } \\
\text { Mild: } \mathrm{He} / \mathrm{she} \text { can put } 3 \text { activities in order. } \\
\text { Moderate: } \mathrm{He} / \text { she can put } 2 \text { activities in order. } \\
\text { Severe: } \mathrm{He} / \text { she cannot put any activities in order. }\end{array}$ \\
\hline $\begin{array}{l}\text { 28- Decrease in starting a task or motivation } \\
\text { Decreased initiative in tasks and activities, failure to sustain tasks given, } \\
\text { difficulty in overcoming the problems } \\
\text { Evaluation whether he/she is enthusiastic during test execution, fulfills the } \\
\text { tasks given or participates. }\end{array}$ & $\begin{array}{l}\text { None: Complete participation during the test execution } \\
\text { Mild: He/she is reluctant during test execution, but he/she completes the test. } \\
\text { Moderate: Weak in the application of test directions. Motivation or repetition } \\
\text { is required. } \\
\text { Severe: The test is executed with difficulty. Insufficient participation. He/she } \\
\text { insufficiently fulfills most of the directions or does not want to do them. }\end{array}$ \\
\hline $\begin{array}{l}\text { 29- Tendency to rapid mental fatigue (observational) } \\
\text { Rapid fatigue in cognitive tasks or complex activities, lethargic } \\
\text { Question: Did you have difficulty during the interview? In which questions? }\end{array}$ & $\begin{array}{l}\text { None: } \mathrm{He} / \mathrm{she} \text { does not get bored with the questions during the test } \\
\text { Mild: } \mathrm{He} / \mathrm{she} \text { starts to get bored in the last part of the questions. } \\
\text { Moderate: He/she starts to get bored with the first part of the questions. } \\
\text { Severe: } \mathrm{He} / \mathrm{she} \text { starts to get bored from the first question. }\end{array}$ \\
\hline
\end{tabular}

